\title{
Study on the NPP Containment Structure Subjected to Different Loading Conditions
}

\author{
Priya Arjunsinh Mahida, Dimple Desai
}

\begin{abstract}
This paper scrutinizes the available research paper and represents a technical overview on NPP containment structure for different conditions such as Seismic loading, Internal over pressure loading and High temperature. Experimental research such as Finite element seismic analysis of RC containment shell, Internal overpressure and leakage performance assessment of hybrid containment structure, behavior of containment structure under high temperature and simulation of containment structure for internal pressure plus temperature loading has been studied extensively in this research. Based on that, factors plays important role in containment structure analysis are highlighted in summary. This study ends with acknowledging the area of research work for evaluating the structural response of containment shell.
\end{abstract}

Index Terms - Long term performance, Non-linear dynamic analysis, NPP containment structure.

\section{INTRODUCTION}

Nuclear Power Plant (NPP) containment structure is the last physical barrier against the release of radioactivity gas or steam to protect the public and environment in case of normal operation, design basis accidents, potential severe accidents and beyond design basis accidents. It is designed to withstand pressure, thermal induced loads, aircraft crash impact and extreme environmental loads produced from earthquakes, tornadoes, hurricanes etc. The containment structure consists cylindrical shell and a dome. The majority of containment structures are made of either reinforced or pre-stressed concrete. Containment structure consist two paramount structural components primary containment structure and secondary containment structure. ${ }^{[3],[4]}$ Primary containment structure acts as a pressure retaining barrier after fuel cladding and reactor coolant pressure boundary. While secondary containment structure is final engineered barrier which protect public environment from the release of radioactive material and primary containment structure from external effect. The objective of this paper is to demonstrate the technical overview of some selected analytical and experimental studies carried out on containment structure

Manuscript revised on October 26, 2019 and published on November 10, 2019

Priya Arjunsinh Mahida, PG Student, Department of Civil Engineering, Uka Tarsadia University, Bardoli, Gujarat, India.

Dimple Desai, Assistant Professor, Department of Civil Engineering, Uka Tarsadia University, Bardoli, Gujarat, India. under seismic loading, internal pressure loading and temperature loading. Following, technical overviews of research work defining the opportunity of subsequent research work.

There are no typical guidelines available for technical parameters of containment structure as the actual materials

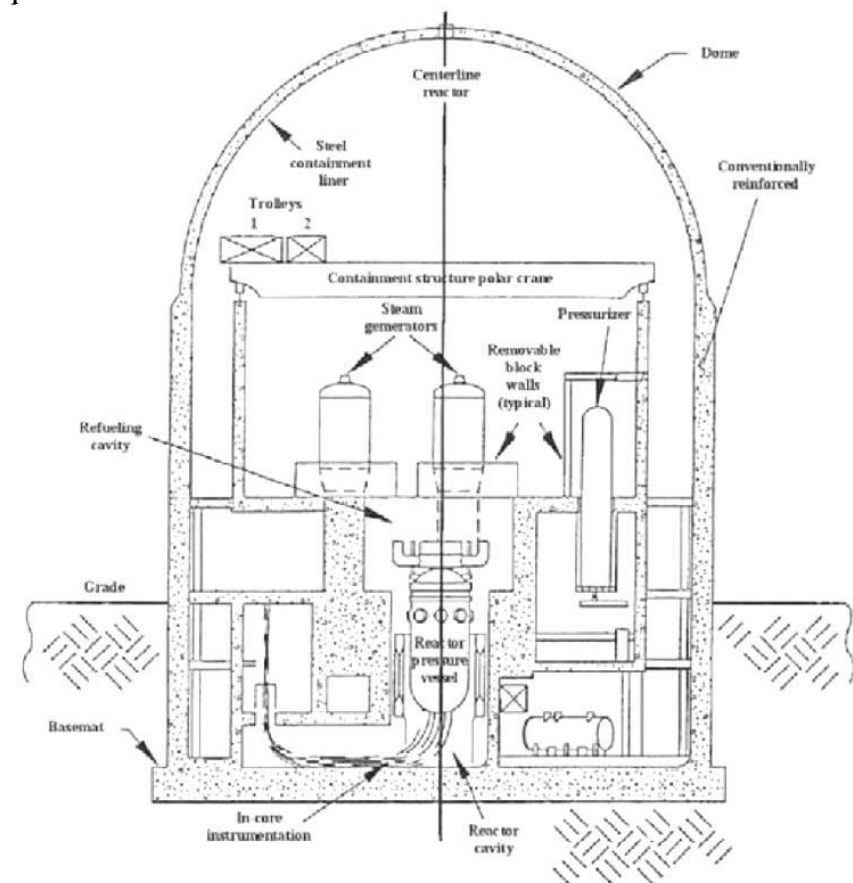

Fig. 1 Typical PWR (Pressurized water reactor) containment structure [11]

and dimensions used for containment shell design depend on type of reactor, structural and project requirements of NPP and many other aspects during present time. But here attention is focused on the technical parameters of containment structure designed during conventional period for understanding purpose.

Here, these technical parameters are for the typical PWR (pressurized water reactor) reinforced concrete containment structure. The cylindrical portion of shell consists 130 to 150 $\mathrm{ft}$ of diameter with 4 to $5 \mathrm{ft}$ thick wall having 140 to $170 \mathrm{ft}$ height from the top of the mat to the bend line. The mat foundation is 10 to $12 \mathrm{ft}$ thick and 150 to $300 \mathrm{ft}$ in diameter. The diameter of mat is generally depending upon whether it supports only containment structure or other safety related structure of NPP. The dome is generally $2 \frac{1 / 2}{\mathrm{ft}}$ thick. ${ }^{[1]}$

The cylindrical portion of steel liner is $3 / 8$ inch thick and dome liner $1 / 2$ inch thick to facilitate concrete pouring during construction. The liner covering mat is $1 / 4$ inch thick. The liner on the mat is protected from temporary thermal loads and internal missiles by a $2 \mathrm{ft}$ layer of concrete poured on and 
anchored to the structural mat. Generally, ultimate strength of concrete and yield stress of reinforcement and liner used in containment shell ${ }^{[\mathrm{I}]}$ in pound per square inch (psi) are:

Concrete : 3000 to 4000 psi at 28 days

Reinforcing steel : 40,000 psi (for $11 \varnothing$ bar and smaller bar) and 60,000 psi (for $14 \varnothing$ and $18 \varnothing$ bar)

Liner : 32,000 psi

Flat plate bars : 50,000 psi

Anchor studs : 50,000 psi

\section{REVIEW OF RELEVANT LITERATURE}

M. Manjuprasad, S. Gopalakrishnan, T.V.S.R. Appa Rao $^{[6]}$ conducted Non-linear dynamic analysis on RC (Reinforced Concrete) secondary containment structure under seismic loading considering non-linearities of reinforced concrete. They used 20 noded, three dimensional, solid isoparametric finite element for modeling. The smeared approach was used for modeling of reinforcement within the thickness of solid element. For non-linear analysis, they adopted new-mark ${ }^{[9]}$ implicit integration method. Computer programme was implemented using computational procedure given by Cervera et al and validated by analyzing the benchmark problem of an RC clamped slab reported by Stangenberg. They carried out non-linear analysis of containment shell for elastic limit of concrete in compression $f \mathrm{c}=0.3 \mathrm{fc}$ and dynamic modulus of elasticity of concrete, $E \mathrm{~d}=447500 \mathrm{~kg} / \mathrm{cm}^{2}$ time step of $\mathrm{d} t=0.01 \mathrm{~s}$ with a total of 1020 steps considering 0.05 tolerance. They presented result in the form of horizontal displacement- time plot at critical point A. From the study, they concluded that elastic limit of concrete in compression controls the onset of the failure phase of concrete by crushing, and the assumption of an appropriate value for the elastic limit of concrete is therefore important to simulate the structural behavior of shell structures subjected to seismic loading up to failure and dynamic modulus of elasticity of concrete plays a important role in the non-linear dynamic analysis as it affects the response and ultimate failure of the containment shell.

Moloy K Chakraborty, Sourav Acharya, Ajai S Pisharady, A. D. Roshan and L. R. Bishnoi ${ }^{[7]}$ carried out performance assessment of hybrid RCC-PSC (Reinforced cement concrete - Prestressed concrete) containment structure of Rajasthan Atomic Power Station unit under internal over-pressure loading and evaluated containment leakage rates. They used ABAQUS software for finite element analysis. They used four noded layered shell elements with reduced integration scheme for finite element modeling. They adopted $0.5 \mathrm{~m}$ element size. Also, average pre-stress load of $25 \%$ for pre-stressing cable was considered for period operational life. They apply pre-stress load than after dead load and subsequently internal pressure load on entire inner surface of containment structure till it reached to the failure criteria. Structural responses obtained from analysis were used to estimate the leak rate for different stages of pressure loading. From the analytical results, they plotted graph of variation in leakage rate of containment structure. They concluded that appearance of first crack in concrete of containment structure occurred at $1.2 \mathrm{Pd}$. Moreover, leakage initiated around 1.5 Pd and progressed linearly with an increment in internal pressure up to $1.85 \mathrm{Pd}$.
C.E. Majorana, F. Pesavento, B.A. Schrefler, D. Gawin ${ }^{[I I]}$ investigated behavior of concrete structure of pre-stressed concrete containment in terms of moisture content, thermal fields, mechanical and thermo-chemical degradation during Loss of Coolant Accident (LOCA). For that, they carried out numerical simulation of pre-stressed concrete containment to assess the capacity of it to prevent leakage and assure its tightness. In their numerical simulation, they considered cylindrical body with a diameter of $45 \mathrm{~m}$, height of $54 \mathrm{~m}$ and thickness of $1.22 \mathrm{~m}$ covered with $1.07 \mathrm{~m}$ thick spherical dome. They assumed heat and moisture exchange at internal surface with $1300 \mathrm{~Pa}$ constant vapor pressure and temperature increasing to $140^{\circ} \mathrm{C}$ during first 5 minutes, then with the constant rate of $2 \mathrm{~K} / \mathrm{min}$. Also, gas pressure increased linearly to the 0.43 bar for first 5 minutes, then at a rate of $0.03 \mathrm{bar} / \mathrm{h}$. In their study, they observed the high gradients of gas pressure and temperature close to the inner surface during initial period. They predicted that after 57 hours surface temperature reached to $270 \mathrm{o} C$ and gas pressure inside the structure reached to $2.3 \mathrm{MPa}$. From which, they concluded that high gradients of temperature and gas pressure were reason to the progressive concrete cracking and after some hours ortho-radial tension stresses were observed in external part of PCC, which was the cause of crack development in that particular zone. Moreover, the final values of mechanical damage parameter were found 57 $\%$ despite of lower temperature and unchanged strength properties compared to the initial period. Hence, they stated that mechanical cracking and thermo-chemical material degradation can affect the concrete permeability and tightness of the containment structure.

Il Hwan Moon, Yong Il Lee, Yong San Yoon, Tae Yong Kim $^{[5]}$ studied non-linear analysis of containment structure of Korean Next Generation Reactor under severe accidental loading condition of temperature and pressure with ABAQUS computer programme. Both material and geometric non linearity were considered in the analysis with menetrey William criterion considering non-associated flow potential. They generated axi-symmetrical model of pre-stressed concrete containment which consists 2064 elements and 1773 nodes. For the analysis, they adopted 1.0 $\mathrm{D}+1.0 \mathrm{~F}+1.0 \mathrm{~T}+1.0 \mathrm{P}$ Load combination where, $\mathrm{D}$ is the dead weight of structure, $\mathrm{F}$ is pre-stressing load, $\mathrm{T}$ is the temperature loading and $\mathrm{P}$ is the internal pressure loading. Moreover, in their study for ultimate pressure assessment they considered three cases which was ultimate pressure assessment without temperature loading, considering 280 degrees internal temperature and considering 450 degrees internal temperature. Also hoop tendons reached to the $1 \%$ of strain at an internal pressure of 208.2 psi for without temperature loading, 203.1 psi for 280 degrees internal temperature and 202.2 psi for 450 degrees internal temperature. Lastly, they concluded that hoop membrane section near the mid height of containment wall was found to be critical and ultimate pressure was reduced when temperature loads were considered hence, they predicted that temperature load should be considered in the load combination to determine ultimate pressure capacity of the containment under severe accident condition. 


\section{SUMMARY}

Being an important barrier to the population and environment, containment structure must have strength and capability to perform and maintain its structural adequacy as well its leak tightness under extreme conditions. Based on referred literature review, it is observed that elastic limit of concrete, dynamic modulus of elasticity plays important role in simulating behavior of containment structure. Also, temperature load must be included to determine ultimate pressure capacity of containment structure. Moreover, structural response of containment structure is well predicted when material nonlinearity and geometric nonlinearity is considered.

\section{Conclusion}

Usage of containment structure is expanding world-wide with increasing need of electricity. Hence, for realistic and safe design of containment structure non linear dynamic simulation must be carried out to evaluate actual performance and leakage rate under seismic load beyond design basis earthquake, internal pressure load beyond design pressure and high temperature loading for potential severe accident condition. Moreover, aging effect should be considered to determine long term performance of containment structure as its design life is 40 years. Moreover, from the above studied literature crack is observed at 1.5 Pd (Design Pressure) for hybrid containment structure.

\section{REFERENCES}

[1] A.K.Banerjee, K.A.Condon, R.A.Rettig, C.F.Reeves, "Design of reinforced concrete containments," Presented at the Transcations Fourth International Conference on Structural Mechanics in Reactor Technology, San Francisco, California, June 13, 1977.

[2] C.E. Majorana, F. Pesavento, B.A. Schrefler, D. Gawin, "Computational analysis of nuclear containment structures at high temperature," Presented at the 2nd International RILEM Workshop on Life Prediction and Aging Management of Concrete Structures, Paris, May 5-6, 2003.

\section{AUTHORS PROFILE}

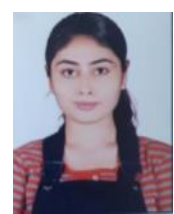

Priya Arjunsinh Mahida currently a final year M. Tech student of Structural Engineering at CGPIT engineering college affiliated to Uka Tarsadia University. She completed her B.E. Civil Engineering from SNPIT Engineering college affiliated to Gujarat Technological University. She is highly focused on her research work and a competent academic career. She has done projects on water distribution network. She also prepared spreadsheet on analysis of cylindrical shell and review study on structural optimization of spacecraft structure. Currently she is working on Finite element Analysis of Nuclear containment structure.

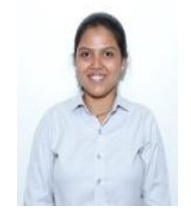

Dimple Desai has received B.E degree in Civil Engineering in 2014 and M. Tech degree in 2016. Currently she is working as an Assistant Professor in Chhotubhai Gopalbhai Patel Institute of Technology Engineering college affiliated to Uka Tarsadia University. She has published research paper in National and International journal. Also, she has attended various seminars and conferences. Her areas of interest for research work are Structural Engineering, Soil Mechanics, Earthquake Engineering and Pre-stressed Concrete Structures.
[3] Civil Engineering Structures Important to Safety of Nuclear Facilities, AERB SAFETY STANDARD NO. AERB/SS/CSE 1998, Atomic Energy Regulatory Board, Mumbai, India.

[4] General design Principles for Nuclear Power Plant, IAEA Safety Guide No.50-SG-D11-1982, International Atomic Energy Agency, Vienna, Austria.

[5] Il Hwan Moon, Yong Il Lee, Yong San Yoon, Tae Yong Kim,"Nonlinear analysis for ultimate pressure capacity assessment of a prestressed concrete containment considering thermal effects," Presented at the Transactions 15th International Conference on Structural Mechanics in Reactor Technology, Seoul, South Korea, August 15-20, 1999.

[6] M. Manjuprasad, S. Gopalakrishnan, T.V.S.R. Appa Rao, "Non-linear dynamic response of a reinforced concrete secondary containment shell subjected to seismic load," Engineering Structures 23 397-406, May 2001

[7] Moloy K Chakraborty, Sourav Acharya, Ajai S Pisharady, A. D. Roshan and L. R. Bishnoi, "Performance assessment of a hybrid RCC-PSC containment for internal over-pressure loading," Presented at the Transactions 24th International Conference on Structural Mechanics in Reactor Technology, BEXCO, Busan, Korea, August 20-25, 2017.

[8] M.Y.H. Bangash, Structures for Nuclear Facilities, Springer-verlag, Berlin Heidelberg 2011, Ch.1, PP. 1-57.

[9] Newmark NM. A method of computation for structural dynamics, ASCE, J Eng Mech Div 1959;85, PP. 67-94.

[10] Safety and Seismic Classification of structures, systems and components",AERB Draft No. AERB/SG/D-1 1998, Atomic Energy Regulatory Board, Mumbai, India.

[11] U.S.N.R.C, "Aging of Concrete and Civil structures" NUREG/CR-7153 Vol.4, United States Nuclear Regulatory Commission, California. 